\title{
Perspective: Point/Counterpoint DSM-IV Depression with Atypical Features: Is It Valid?
}

\author{
Jonathan W Stewart*, ${ }^{*}, 2$, Patrick J McGrath ${ }^{1,2}$, Frederic M Quitkin" and Donald F Klein ${ }^{2}$ \\ 'Department of Depression Evaluation Service, New York State Psychiatrist Institute, New York, NY, USA; ${ }^{2}$ Department of Psychiatry, Columbia \\ University, College of Physicians and Surgeons, New York, NY, USA
}

\begin{abstract}
Atypical features were incorporated into the American Psychiatric Association's Diagnostic and Statistical Manual, Fourth Edition (DSM-IV, 1994) as an illness specifier for major depression and dysthymia. The validity of depression with atypical features was supported by differences relative to depression with melancholic features in syndromal symptoms, course of illness, biology, family history, and treatment response. This paper reviews post-DSM-IV literature relevant to the validity of depression with atypical features. Most studies support the pre-DSM-IV findings. Again, course of illness, biological, family, and treatment differences are shown between melancholia and depression with atypical features. Several biologic studies report nondepressed controls have mean values between depressed subjects having atypical features and other depressed patients. This suggests atypical depression is a distinct depressive group rather than a milder form of melancholia. In addition, some studies show distinctions between depressed subjects with atypical features and those having neither atypical nor melancholic features. As depression with atypical features separates not only from melancholia but also from other depressed groups and controls over a range of meaningful distinctions, we conclude it is a valid clinical syndrome, useful both heuristically and in driving treatment decisions.

Neuropsychopharmacology (2009) 34, 2625-2632; doi:I0.1038/npp.2009.99; published online 2 September 2009
\end{abstract}

Keywords: atypical depression; validity; nonmelancholic depression; DSM-IV specifiers

\section{INTRODUCTION}

This review focuses on post-1994 studies addressing the validity of the atypical features specifier for depressive illness as defined by the Diagnostic and Statistical Manual, Fourth Edition (DSM-IV) (APA, 1994). The historical context of atypical depression and validating studies published before 1994 have been adequately summarized (Stewart et al, 1993; Rabkin et al, 1996; Lam and Stewart, 1996). The current review follows the outline for establishing syndrome validity proposed by Robins and Guze (1970), as amended by Klein (1989) and Kendell (1989). Robins and Guze proposed that validation of psychiatric syndromes requires investigations into five areas of psychopathology: symptoms, biology, family history, course of illness, and differential diagnosis (ie, using the other four areas to distinguish the proposed syndrome from established syndromes). The more psychopathologic areas in which two syndromes differ, the more likely the syndromes' pathophysiologies differ.

Klein (1989) introduced 'pharmacologic dissection' as an additional validating criterion. Klein observed that effective treatments normalize pathologic symptoms while produ-

*Correspondence: Dr JW Stewart, I05I Riverside Drive, New York State Psychiatric Institute, I05 I Riverside Drive, New York, NY, 10032, USA, Tel: + | 212543 5745, Fax: + | 2125435326 ,

E-mail: jws6@columbia.edu

"Dr Quitkin died on 9 October 2005.

Received 7 August 2006; accepted 10 November 2006 cing little but side effects in normals. For example, lithium removes manic symptoms but does not make those without bipolar disorder depressed. Insofar as they normalize those afflicted while having little effect on normals, effective pharmacological agents can be assumed to directly affect the underlying pathophysiology specific to the disorder. Thus, pharmacological dissection posits that if patients with similar symptoms have substantively different benefits from a pharmacological intervention, pathophysiological differences are implied. Therefore, differential treatment response can validate syndromal distinctions.

Kendell (1989) argued that true biological distinctions should show points of rarity. That is, some biological measure should cluster around high or low values with few measurements in between. However, the hallmark measurements of many illnesses (eg, hypertension, diabetes) appear on a continuum with normality, yet are considered distinct illnesses. Points of rarity imply biological difference, but failure to show them does not rule out a pathophysiological difference. This should be especially true for psychiatric illnesses where the pathophysiology is unknown or poorly understood.

Does the post-DSM-IV literature confirm the validity of depression with atypical features? We will address each of the Robins and Guze criteria, as amended, to determine whether studies distinguish depressed patients with atypical features from those with melancholia. In addition, we will consider whether atypical depression can also be distinguished from other nonmelancholic depression, that is, 
Table I Definitions

Atypical depression/depression with atypical features. These terms are used interchangeably to refer to the depressive group defined by the DSM-IV criteria for depression with atypical features. First, major depression or dysthymia must be present. Second, there must be significant mood reactivity. Third, two of the four associated symptoms (from among: hyperphagia, hypersomnia, leaden paralysis, and rejection sensitivity) must be present to a significant degree. Finally, patients cannot also meet criteria for catatonic or melancholic features during the same depressive episode

Melancholialdepression with melancholic features. These terms interchangeably denote subjects meeting DSM-IV criteria for depression with melancholic features. Major depression must be present, as well as either nearly pervasive anhedonia or mood nonreactivity. Subjects must also report three of six additional symptoms: a distinct quality to their mood (i.e., that it is not similar to grief), significant early morning wakening, excessive or inappropriate guilt, significant anorexia or weight loss, morning worsening and marked psychomotor agitation, or retardation. For symptoms duplicating criteria for major depression, thresholds are higher for melancholic features. For example, early morning wakening must be at least $2 \mathrm{~h}$ too early virtually every day.

Undifferentiated depression. These are patients meeting DSM-IV for a depressive disorder who have neither atypical nor melancholic features. In general, these patients also do not have psychotic, catatonic, or seasonal features, but this is not always explicitly stated in the cited studies.

from depressed patients having neither melancholic nor atypical features. Although distinguishing atypical depression from melancholia comports with the Robins and Guze requirement of distinguishing a proposed syndrome from an established one, its distinction from other nonmelancholic depression would help establish its potential utility beyond imperfectly identifying patients who do not have melancholic illness (Parker et al, 2002).

Table 1 defines the relevant terms used in this discourse.

\section{POST-1994 VALIDITY OF DSM-IV DEPRESSION WITH ATYPICAL FEATURES}

\section{Symptoms}

Depressive symptoms distinguish melancholic and atypical features by definition and, therefore, do not lend themselves to validity testing. It is perhaps surprising, however, that nondefinitional symptoms, such as feelings of worthlessness and diurnal variation, have not been investigated.

\section{Biological Studies}

McGinn et al (1996), (see Table 2), studied 114 patients with major depression, including 33 with atypical features, 29 with mood reactivity but without atypical features, and 52 without significant mood reactivity. Many in the latter group may be assumed to have melancholic features as $98 \%$ met the Research Diagnostic Criteria (Spitzer et al, 1978) for endogenous depression. Cortisol was measured before and after $75 \mathrm{mg}$ desipramine given intramuscularly. A previous study showed blunted cortisol response to desipramine in depressed patients with melancholic features compared with never depressed controls (Asnis et al, 1985). If depression with atypical features shares the biology of melancholia, cortisol response to desipramine should also be blunted in patients with atypical depression. Instead, McGinn et al (1996) found that the desipramine-induced cortisol response was significantly less blunted in depressed patients with atypical features relative to other depressed subjects. Although nondepressed controls were not included in the McGinn et al report, those with atypical depression had cortisol responses to desipramine similar to values of the published never depressed controls. This suggests that patients with atypical depression do not have the HPA abnormality common to melancholia, at least as measured by cortisol response to desipramine. Nonatypical patients with and without mood reactivity did not differ, both groups having cortisol responses to desipramine that approximated the published reports for melancholia, and blunted relative to the published reports for controls (Asnis et al, 1985). A strength of the McGinn et al study is the separation of those without atypical features into mood reactive and mood nonreactive groups. The mood reactive group would not meet DSM-IV criteria for melancholic features, thus represents the critical undifferentiated group. Limitations include lack of a never depressed comparison group. Also, although patients with mood nonreactive depression conceptually have melancholia (Klein, 1974), McGinn et al did not identify which patients had melancholic features.

Geracioti et al (1997) measured cerebrospinal fluid (CSF) corticotropin-releasing hormone $(\mathrm{CRH})$ in 10 depressed patients, 'the majority of whom had at least one 'atypical' symptom', and 15 never depressed, age- and sex-matched controls. Cortisol, adrenocorticotropin hormone (ACTH), and $\mathrm{CRH}$ are hypersecreted in melancholia (Wong et al, 2000). If atypical depression is a milder form of melancholia, depressed subjects with atypical features should show elevated CSF CRH. Contrary to this expectation, Geracioti et al reported significantly lower CSF CRH in this group of depressed patients than in controls. Plasma cortisol was normal, and plasma ACTH tended (ie, $p<0.1$ ) to be low. The Geracioti et al study is limited, in that the DSM-IV criteria for atypical features were not assessed. In addition, a concurrent comparison group with melancholic features would have allowed firmer inferences.

Anisman et al (1999) investigated cortisol, ACTH, epinephrine, norepinephrine, and two cytokines (IL-1 $\beta$ and IL-2) in 74 depressed outpatients and 27 never depressed controls. The depressed subjects were assessed for the presence or absence of atypical features. None had melancholic features. Major depressives with atypical features had decreased morning cortisol relative to undifferentiated major depression and controls. The undifferentiated depressed subjects did not differ from the controls. Strengths of this study include inclusion of a never depressed control group and assessment of depressive subtypes. Weaknesses include lack of a comparison group with melancholia. This study, collectively with the previous studies of HPA axis pathology in atypical depression, raises questions of the central role of hypercortisolemia and/or excessive brain $\mathrm{CRH}$ in the pathophysiology in affective disorder in general. Rather, hypercortisolemia may characterize some depressive disorders, but hypocortisolism may be found in others.

Fountoulakis et al (2004) investigated single-photon emission computerized tomography (SPECT) in 50 depressed patients with DSM-IV major depression, including subtype assessment. Fountoulakis et al reported perfusion in 17 brain regions (see Table 3 ). Patients with melancholic 
Table 2 Biologic Studies Validating DSM-IV Depression with Atypical Features

\begin{tabular}{|c|c|c|c|c|c|}
\hline Study & Test & Subjects & Results & Statistics & Interpretation \\
\hline $\begin{array}{l}\text { McGinn et al } \\
(1996)\end{array}$ & $\begin{array}{l}\text { DMI stimulation } \\
\text { of cortisol }\end{array}$ & $\begin{array}{l}29 \text { NAF w MR } \\
52 \text { NAF wo MR } \\
33 \text { AF }\end{array}$ & $\begin{array}{l}\text { NAF w MR: } 13.90 \pm 1.23 \\
\text { NAF wo MR: } 13.76 \pm 0.88 \\
\text { AF: } 17.67 \pm 1.30\end{array}$ & $\begin{array}{l}F_{2,63}=4.40, p<0.02 \\
A D \text { vs NAF w MF: } \\
F_{1,29}=7.46, p<0.02 \\
\text { AD vs NAF wo MF: } \\
F_{1,45}=10.54, p<0.01 \\
\text { MF vs NAF: NS }\end{array}$ & $A F>N A F w M F=N A F$ wo $M F$ \\
\hline $\begin{array}{l}\text { Bruder et al } \\
(2002)\end{array}$ & Chimeric faces & $\begin{array}{l}9 \mathrm{MF} \\
72 \mathrm{NAF} \\
164 \mathrm{AF} \\
115 \text { controls }\end{array}$ & $\begin{array}{l}\text { MF: } 0.07 \pm 0.48 \\
\text { C: }-0.27 \pm 0.52 \\
\text { AF: }-0.42 \pm 0.42 \\
\text { NAF: }-0.24 \pm 0.54\end{array}$ & $\begin{array}{l}\text { Left visual field bias: } \\
\text { AF vs C: } p<0.05 \\
\text { AF vs NAF: } p<0.05 \\
\text { NAF vs C: NS } \\
\text { MF vs C: } p<0.05 \\
\text { MF vs NAF: NS }\end{array}$ & $\begin{array}{l}\text { Preference for smile on left: } \\
A F>\text { controls }=N A F \geqslant M F^{b}\end{array}$ \\
\hline $\begin{array}{l}\text { Fotiou et al } \\
\text { (2003) }\end{array}$ & PR-VEP & $\begin{array}{l}50 \mathrm{MDD} \\
\quad-14 \mathrm{AF} \\
-16 \mathrm{MF} \\
20 \text { controls }\end{array}$ & $\begin{array}{l}\text { N80 midline latency } \\
\text { AF: } 69.00 \pm 3.55 \\
\text { C: } 75.70 \pm 5.00 \\
\text { MF: } 76.97 \pm 4.78 \\
\text { PI00 midline latency } \\
\text { AF: } 96.53 \pm 3.42 \\
\text { MF: } 109.36 \pm 8.30 \\
\text { C: } 103.60 \pm 6.65\end{array}$ & $\begin{array}{l}\text { N80 midline latency } \\
\text { AF vs MF: } F_{1,30}=18.93, \\
p<0.001 \\
\text { PI00 midline latency } \\
\text { AF vs MF: } F_{1,30}=15.04, \\
p<0.00 \text { I comparisons } \\
\text { with controls not shown }\end{array}$ & $\begin{array}{l}\text { N80 and PI00 latency: } \\
\text { AF }<\text { MF } \\
\text { controls had 'intermediate' values } \\
\text { (ie, between those of AF and MF) }\end{array}$ \\
\hline
\end{tabular}

$\mathrm{ACTH}$, adrenocorticotropin hormone; $\mathrm{AF}$, depression with atypical features; $\mathrm{C}$, controls; $\mathrm{CRH}$, corticotrophin-releasing hormone; DMI, desmethylimipramine; MDD, major depressive disorder; MF, depression with melancholic features; MR, mood reactivity; NAF, depression without atypical features; NAF/NMF, depression with neither melancholic nor atypical features; PR-VEP, pattern reversed visual evoked potential; SPECT, single photon emission computerized tomography.

'The 'majority with' AF.

${ }^{b}$ Depressed patients with melancholic features had significantly less preference for smiles presented on the left than controls, did not differ from depressed patients with neither atypical nor melancholic features.

features $(N=16)$ and undifferentiated depressed subjects $(N=20)$ each differed from controls $(N=20)$ in 10 brain regions, but did not differ from each other in any of the 17 regions. In contrast, atypically depressed patients $(N=14)$ differed from those with melancholia in nine regions and from undifferentiated patients in 10 regions, while showing differences from controls in five brain regions. In two brain regions, patients with atypical depression differed from both controls and at least one of the other depressed groups. The overall picture was that relative to the other two depressed groups, those with atypical depression had increased frontal, temporal, and parietal perfusion coupled with decreased occipital perfusion. Relative to controls, patients with atypical depression also had increased right frontal perfusion, whereas those with melancholia and undifferentiated depression had decreased perfusion in the majority of nonoccipital regions. Thus, all three depressed groups showed abnormal perfusion, but the patterns differed. Melancholia and undifferentiated depression had similar patterns of abnormal perfusion that differed from those with atypical depression. Strong points of this study included assessment of diagnoses according to DSM-IV criteria, including assessment of both melancholic and atypical features, and inclusion of comparison groups of controls and subjects having undifferentiated depression. A weakness is that the controls are not further described.

Bruder et al (2002) assessed chimeric faces as a measure of perceptual asymmetry. A chimeric face consists of fusion of a neutral right half-face with a smiling left half-face. Its mirror image (creating a neutral left half-face fused with a smiling right half-face) is randomly placed above or below. The task is to quickly determine which of the two faces is happier. Preference for choosing one side as happier relative to the other has been interpreted as reflecting increased activation of the contralateral parietal lobe (Heller, 1993), although inhibitory mechanisms could also be hypothesized. As patients with atypical depression had been shown to have a different auditory asymmetry than those with melancholia (Bruder et al, 1989), it was hypothesized that these groups would also differ on this visual task. 
Table 3 Perfusion Findings of Fountoulakis et al (2004)

M vs C U vs C A vs C A vs M As U M vs U

\begin{tabular}{|c|c|c|c|c|c|}
\hline \multicolumn{6}{|l|}{ Brain stem } \\
\hline Right frontal & & & $\uparrow$ & $\uparrow$ & $\uparrow$ \\
\hline Left frontal & $\downarrow$ & & & $\uparrow$ & \\
\hline Right parietal & $\downarrow$ & $\downarrow$ & $\downarrow$ & & \\
\hline Left parietal & $\downarrow$ & $\downarrow$ & $\downarrow$ & & \\
\hline Right medial temporal & $\downarrow$ & $\downarrow$ & & $\uparrow$ & $\uparrow$ \\
\hline Left medial temporal & & $\downarrow$ & & $\uparrow$ & $\uparrow$ \\
\hline Right lateral temporal & $\downarrow$ & $\downarrow$ & & $\uparrow$ & $\uparrow$ \\
\hline Left lateral temporal & $\downarrow$ & $\downarrow$ & & $\uparrow$ & $\uparrow$ \\
\hline Right occipital & & & & $\downarrow$ & $\downarrow$ \\
\hline Left occipital & & $\downarrow$ & $\downarrow$ & $\downarrow$ & \\
\hline Right thalamus & & & & & $\uparrow$ \\
\hline Left thalamus & $\downarrow$ & & $\downarrow$ & & \\
\hline \multicolumn{6}{|l|}{ Right globus pallidus } \\
\hline Left globus pallidus & $\downarrow$ & $\downarrow$ & & & $\uparrow$ \\
\hline Right caudate & $\downarrow$ & $\downarrow$ & & & $\uparrow$ \\
\hline Left caudate & $\downarrow$ & $\downarrow$ & & $\uparrow$ & $\uparrow$ \\
\hline
\end{tabular}

Bruder et al (2002) reported that depressed patients with atypical features were significantly more likely than never depressed controls to report the chimeric face with the smile on the left to be happier. This may indicate relatively increased right parietal processing (Heller, 1993). In contrast, depressed patients without atypical features were significantly less likely than those with atypical features to report the left-sided smile to be happier.

Decreased preference for the left-sided smile was especially strong for the nine patients with melancholic features, who showed significantly increased favoring of right-sided smiles relative to never depressed controls, but did not differ significantly from patients with undifferentiated depression. Controls' ratings fell between those of the patients with melancholia and those with atypical features. In agreement with the Fountoulakis study, depressed patients with neither atypical nor melancholic features were more similar to those with melancholia than patients with atypical features. The strengths of the Bruder et al study are inclusion of comparison groups of never depressed controls and of a group with undifferentiated depression. A conceptual problem unresolved by the Bruder et al results is the status of undifferentiated depression, as undifferentiated patients did not differ from either controls or patients with melancholia. Thus, whether undifferentiated patients are 'normal' or should be considered with those having melancholia is not resolved by these data, possibly because of few subjects with melancholia $(N=9)$.

Fotiou et al (2003) assessed pattern-reversed visual evoked potentials in 50 subjects with major depression and 20 controls using EEG evoked potential measurements after a visual stimulus. DSM-IV atypical and melancholic features were assessed in the depressed subjects. N80 and
P100 latencies were significantly shorter in depressed subjects with atypical features $(N=14)$ than in control subjects. In contrast, those with melancholic features $(N=16)$ had significantly prolonged $\mathrm{N} 80$ and P100 latencies relative to controls and depressed subjects with atypical features. Thus, controls again lay between the two depressive subtypes. Fotiou et al did not report results for the patients with undifferentiated depression.

These six studies are consistent, suggesting that atypical depression does not have the biological features of melancholia. Four studies show significant differences between atypical and undifferentiated depression, and none found undifferentiated depression to differ from melancholia. Furthermore, control means often lie between those of patients with atypical depression and the other two depressed groups. Thus, depression with atypical features appears a biologically distinct group, arguing for its discriminant validity.

\section{Course of Illness}

In their validity review for the DSM-IV Affective Disorders Task Force (see Table 4), the Columbia group reported earlier onset and a more chronic illness in research patients with atypical depression compared with patients with melancholia (Stewart et al, 1993). Subsequent studies of treatment-seeking patients also found patients with atypical depression have an earlier age of onset (Posternak and Zimmerman, 2002; Perugi et al, 1998; Benazzi, 1999) and a more chronic illness (McGinn et al, 1996; Posternak and Zimmerman, 2002) than other depressed patients. Corroboration by epidemiological studies (Angst et al, 2002; Matza et al, 2003; Kendler et al, 1996) suggests these findings are not artifacts of self-selection or referral bias. Despite occasional discrepancies (Benazzi, 1999; Asnis et al, 1995), the preponderance of evidence is that early onset and chronic illness characterize atypical depression relative to other depressed patients.

Course of illness can also be characterized by determining consistency of symptoms and depressive subtype on different occasions. Clearly, illnesses can present differently on different occasions (eg, bipolar disorder, syphilis), but consistency of symptoms over time suggests that core features are being assessed. Nierenberg et al (1996) reported 32 remitted depressed patients who later became depressed again. At relapse or recurrence, $76 \%$ had vegetative symptoms similar to initial presentation. Concordance was high whether initial symptoms were atypical (ie, hyperphagia/hypersomnia) or typical of melancholia (ie, anorexia/insomnia).

Kendler et al (1996) re-interviewed over 1000 female twin pairs a year after an initial interview; each interview assessed the previous 12 months. In twins reporting depression during both years, $73 \%$ reported the same symptoms (ie, atypical vs. typical) at the second interview as they had initially.

In 1978, Angst et al (1984) identified nearly 400 Zurich 19- to 20 -year olds who rated themselves above the 85 th percentile on the depression subscale of the SCL-90 (Derogatis, 1977) from among a much larger epidemiological sample. This enriched community sample was reinterviewed four times over 7 years (Angst et al, 2002). 
Table 4 Age of Onset and Chronicity in Atypical Depression

\begin{tabular}{|c|c|c|}
\hline & $\begin{array}{l}\text { Age of onset } \\
\text { (years) }\end{array}$ & Chronicity \\
\hline \multicolumn{3}{|l|}{ Stewart et al (1993) } \\
\hline Atypical depression & $17 \pm 27$ & $\begin{array}{l}227 \pm 215 \text { months } \\
\text { (current episode) }\end{array}$ \\
\hline Melancholia & $32 \pm 17^{0.001}$ & $46 \pm 102^{0.001}$ \\
\hline \multicolumn{3}{|c|}{ Posternak and Zimmerman (2002) } \\
\hline Atypical depression & $23 \pm 12$ & $\begin{array}{l}349 \pm 726 \text { weeks } \\
\text { (current episode) }\end{array}$ \\
\hline Nonatypical depression & $27 \pm 14^{0.003}$ & $205 \pm 4 \mid 4^{0.03}$ \\
\hline \multicolumn{3}{|l|}{ Perugi et al (1998) } \\
\hline Atypical depression & $23 \pm 8$ & $\begin{array}{l}13 \pm 16 \text { months (current } \\
\text { episode); } 31 \% \text { chronic }\end{array}$ \\
\hline \multicolumn{3}{|c|}{ No comparison group reported } \\
\hline \multicolumn{3}{|l|}{ Angst et al (2002) } \\
\hline Atypical depression & $12.4^{\mathrm{a}}$ & |36/365 days ${ }^{\mathrm{a}}$ \\
\hline Other depression & $15.1^{0.02}$ & $95 / 365$ days $^{0.02}$ \\
\hline \multicolumn{3}{|l|}{ Benazzi (1999) } \\
\hline Atypical depression & $26 \pm 12$ & $42 \%$ chronic \\
\hline Nonatypical depression & $31 \pm 15^{0.01}$ & $46 \%$ chronic $^{N S}$ \\
\hline
\end{tabular}

${ }^{\mathrm{a} N o}$ standard deviation given.

Depending on which interviews were compared, $67-75 \%$ of subjects diagnosed with 'typical' depression at one occasion were also diagnosed as having typical depression at a second occasion. Overall, $45-65 \%$ of subjects diagnosed as 'atypical' on one occasion were also judged atypical at a second interview. It is unclear whether incongruent subjects manifested too few symptoms at the incongruent interview for either subtype, or met criteria for features of the alternative subtype. Poor inter-rater reliability would limit concordance and reliability was not reported.

The Nierenberg, Kendler, and Angst studies suggest that depressive neurovegetative symptoms are moderately stable, but do not address how often patients shift subtype, especially over longer periods. An alternative hypothesis might be that symptoms are pathoplastic, such that early in life hyperphagia and hypersomnia are more likely, while decades later the same disorder manifests with anorexia and insomnia. Longer follow-up studies, such as that of Angst et al projects, may determine whether patients with early-onset atypical depression will have melancholiaassociated symptoms later in life, or remain with atypical symptoms.

\section{Pharmacological Dissection}

Two studies applied the principles of pharmacological dissection (Table 5). Stewart et al (1998), for example, showed a significant three-way interaction among treatment (imipramine, placebo), subtype (atypical, nonatypical), and treatment response (change in the HAMD score). This was accounted for by those with atypical depression having no better improvement on drug than placebo, whereas patients without atypical depression had a robust imipramine effect.

Joyce et al (2002) randomly assigned 195 patients with major depression to treatment with nortriptyline or fluoxetine. Among patients without atypical depression, the two drugs were equally effective, and did not differ between those with melancholia (fluoxetine response: $56 \%$; nortriptyline response: $39 \%$ ) and with undifferentiated depression (fluoxetine response: 57\%; nortriptyline response: $43 \%)$. In contrast, among patients with atypical depression, fluoxetine was significantly more effective $(4 / 6=67 \%$ responded $)$ than was nortriptyline $(0 / 10=0 \%$; exact $p=0.02)$; the tricyclic antidepressant was also significantly less effective for atypical depression than for other depressed patients. However, the superiority of fluoxetine over tricyclic for atypical depression was not corroborated in a larger study (McGrath et al, 2000). Collectively, these studies corroborate earlier studies suggesting relatively poor tricyclic response in depression with atypical features (Liebowitz et al, 1988; Quitkin et al, 1988; Quitkin et al, 1990).

\section{Family History}

Kendler et al (1996) interviewed over 1000 female twin pairs to assess familiality of disorders. Atypical depression was not directly addressed. However, a latent class analysis applied to 16 depressive symptoms produced four depressive subtypes. Kendler et al considered one subtype to approximate atypical depression as hyperphagia and hypersomnia were common in this group. When monozygotic twins both reported a depressive episode, it was significantly more likely that both or neither was in the atypical subgroup than only one twin. This suggests a familial, possibly genetic, contribution to the etiology of atypical depression, but familiality was not shown in dizygotic twins, possibly owing to lower power.

\section{Points of Rarity}

Lam and Stewart (1996) observed that points of rarity have not been reported for atypical depression, arguing against its validity. However, points of rarity are more persuasive when present than when absent. As biology specific for atypical depression has not been elucidated, it is not surprising that points of rarity have not surfaced, even if they exist.

\section{Summary of Post-DSM-IV Validity}

These studies suggest that patients with atypical depression are distinct from melancholic patients in terms of course of illness, biology, expected treatment response, and familial aggregation. Collectively, these post-DSM-IV studies support the inclusion of an atypical features modifier for DSMIV major depression and dysthymia.

However, Parker et al (2002) argued that comparing atypical depression with melancholia, as was done in the petition for including atypical depression in DSM-IV (Rabkin et al, 1996), is not as instructive as would be a 
Table $\mathbf{5}$ Treatment of Depression with Atypical Features

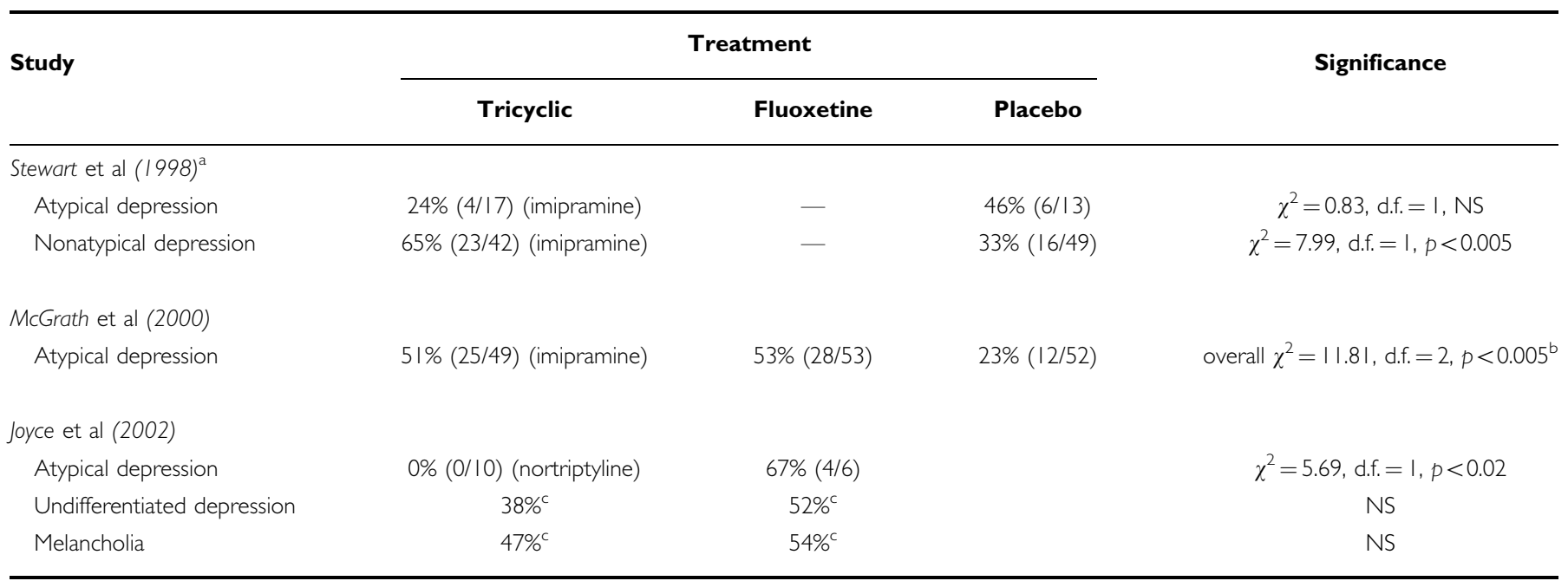

Post-hoc pair-wise comparisons of multi-group significant findings:

anteraction between subtype and treatment: $\chi^{2}=6.58$, d.f. $=1, p<0.0$ ।

IImipramine vs placebo: $\chi^{2}=7.32$, d.f. $=1, p<0.0$ I; fluoxetine vs placebo: $\chi^{2}=8.63$, d.f. $=1, p<0.005$; imipramine vs fluoxetine: NS.

'Proportions were not reported.

Table 6 Pair-wise Differences across Studies among Patients with Atypical Depression, Undifferentiated Depression, Melancholia, and Controls

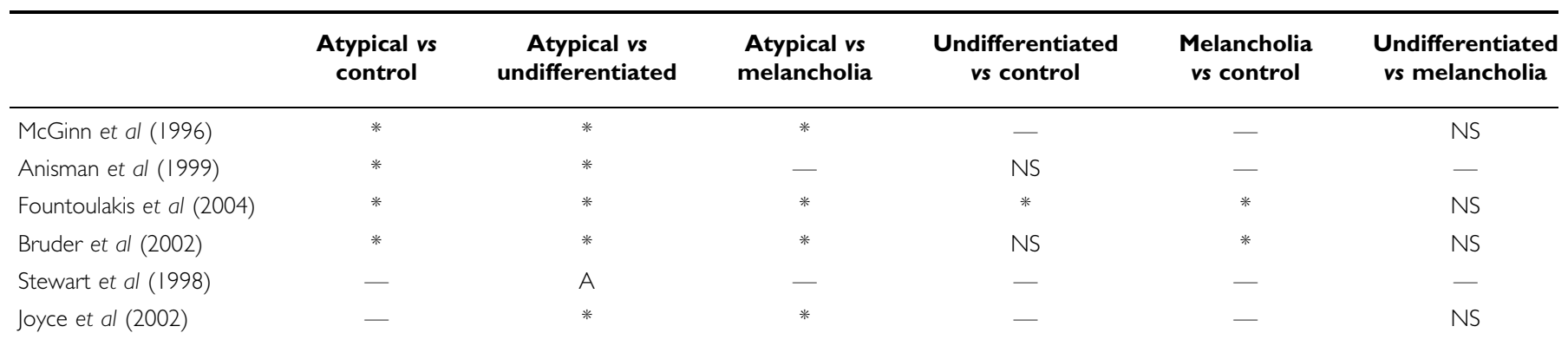

A, patients with atypical depression differed significantly in treatment response from patients without atypical depression; the latter group was not further divided into those with and without melancholia.

*, groups differed significantly.

NS, Groups did not differ significantly.

- one or both groups not included.

comparison between atypical depression and other nonmelancholic depression. Unless atypical depression is differentiated from depressed patients with neither melancholic nor atypical features, applying atypical criteria could be a cumbersome way of saying melancholia is not present. McGinn et al (1996), Anisman et al (1999), Fountoulakis et al (2004), Bruder et al (2002), Stewart et al (1998), and Joyce et al (2002), partially answered the challenge of Parker et al (2002) (see Table 6). All studies compared depressed patients having atypical features with other depressed patients, five including an undifferentiated group having neither melancholic nor atypical features. In all four studies that included patients with melancholic illness, those with atypical features differed (McGinn et al, 1996; Fountoulakis et al, 2004; Bruder et al, 2002; Joyce et al, 2002). In all five studies including an undifferentiated group, those with atypical features differed (McGinn et al, 1996; Anisman et al, 1999; Fountoulakis et al,
2004; Bruder et al, 2002; Joyce et al, 2002). One study did not differentiate which patients without atypical depression had melancholia, but did show good imipramine response in those without atypical depression relative to those with atypical depression (Stewart et al, 1998) (see Table 5 for proportions responding). Furthermore, none of the four studies that reported on both patients with melancholia and undifferentiated patients found differences between these latter two groups. Finally, controls either did not differ significantly from undifferentiated subjects or had values between the nonmelancholic/nonatypical patients and those with atypical features. Collectively, these findings suggest that the important distinction is not between melancholic and nonmelancholic depression but between atypical and nonatypical depression. This distinction within nonmelancholic depression represents further evidence for the validity of atypical depression. 


\section{Clinical Implications}

Regardless of a syndrome's heuristic validity, the ultimate test is its clinical utility. One might argue that a category for chronic depression already exists, namely dysthymia. However, dysthymia is conceptually orthogonal to atypical depression. Furthermore, in one study of atypical depression, presence or absence of dysthymia (or of major depression) was not significant, whereas other variables such as age of onset and chronicity were (Stewart et al, 2002). We are unaware of other studies addressing the relative validity and utility of dysthymia vs. atypical depression. Currently, it appears that atypical depression is more important than dysthymia in predicting treatment outcome.

As tricyclic antidepressants and monoamine oxidase inhibitors are currently little used, clinicians may feel they have little reason to assess patients for atypical features. We argue this is short-sighted. First, it was early noted that electroconvulsive treatment (ECT) is ineffective for patients with atypical depression (Sargant, 1960). We are unaware of definitive corroboration of this observation, but it agrees with our experience. If true, when treatment options for refractory depression come to TCA vs. ECT vs. MAOI, treatment planning should take presence or absence of atypical depression into consideration, as MAOIs are welldemonstrated to be effective for this group, whereas ECT and TCA are not. Thus, although its clinical utility lies later in sequential treatment algorithms, the clinical advantage of assessing atypical features seems apparent.

An additional clinical utility in identifying atypical depression may be in adolescents. TCAs have not been shown to be effective in general in adolescents (Geller $e t$ al, 1999; Hazell et al, 2002), or in depressed adolescents with atypical features (Klein et al, 1998) whereas SSRIs have generally not been effective for depressive illness in children (Mandoki et al, 1997; Keller et al, 2001; Whittington et al, 2004; Wagner et al, 2006) except fluoxetine (Emslie et al, 1997; Emslie et al, 2002; Whittington et al, 2004). The early onset of depressive illness in patients suffering from atypical features likely results in an increased percentage of atypical depression among depressed teenagers, perhaps accounting for these findings. Despite the belief that dietary indiscretion may be increased in adolescents, the likelihood of increased atypical depression in this age group suggests a reappraisal of MAOIs for adolescent depression.

The safer transdermal selegiline (Barrett et al, 1997) and reversible MAOIs, such as moclobemide (Korn et al, 1987), should be considered for patients with atypical depression, especially in depressed adolescents.

\section{CONCLUSIONS}

Atypical depression meets the Robins and Guze (1970) criteria for validity as amended by Klein (1989) and Kendell (1989). Depressed patients meeting the DSM-IV criteria for atypical features differ from those with melancholic features in their symptoms (by definition), course of illness, biology, family history of depressive illness, and treatment response. Although fewer studies address the relationship between atypical depression and other nonmelancholic depression, those that do also suggest atypical depression is a distinct subgroup. In addition, this category may have clinical utility in implementing treatment strategies for refractory depression. For all these reasons, depression with atypical features appears to be a valid entity, useful both heuristically and clinically.

\section{DISCLOSURE}

During the past 3 years, Dr Stewart has received honoraria from Bristol-Myers-Squibb and Pfizer, consulted with Biovail and Merck, and received study support from Eli Lilly. Dr Stewart received no remuneration connected with the writing of this paper or for the work upon which the paper is based. Dr Klein has nothing to disclose. During the past 5 years, Dr McGrath has received research support from the NIMH, NIAAA, NY State Department of Mental Hygiene, NARSAD, Research Foundation for Mental Hygiene (NY), GSK, Eli Lilly, and Organon, Lipha Pharmaceuticals. He has consulted for GSK, Somerset Pharmaceuticals, Novartis, Sanofi-Aventis, and Roche.

\section{REFERENCES}

American Psychiatric Association (1994). Diagnostic and Statistical Manual of Mental Disorders, Fourth Edition. APA: Washington, DC.

Angst J, Dobler-MiKola A, Binder J (1984). The Zurich Study - a prospective epidemiological study of depressive, neurotic and psychosomatic syndromes. I. Problem, methodology. Eur Arch Psychiatry Neurol Sci 234: 13-20.

Angst J, Gamma A, Sellaro R, Zhang H, Merikangas K (2002). Toward validation of atypical depression in the community: results of the Zurich cohort study. J Affect Disord 72: 125-138.

Anisman H, Ravindran AV, Griffiths J, Merali Z (1999). Endocrine and cytokine correlates of major depression and dysthymia with typical or atypical features. Mol Psychiatry 4: 182-188.

Asnis GM, Halbreich U, Rabinovich H, Ryan ND, Sachar EJ, Nelson B et al (1985). The cortisol response to desipramine in endogenous depressives and normal controls: preliminary findings. Psychiatry Res 14: 225-233.

Asnis GM, McGinn LK, Sanderson WC (1995). Atypical depression: clinical aspects and noradrenergic function. Am J Psychiatry 152: 31-36.

Barrett JS, Hochadel TJ, Morales RJ, Rohatagi S, DeWitt KE, Watson SK et al (1997). Pressor response to tyramine after single 24-hour application of a selegiline transdermal system in healthy males. J Clin Pharmacol 37: 238-247.

Benazzi F (1999). Prevalence and clinical features of atypical depression in depressed outpatients: a 467-case study. Psychiatry Res 86: 259-265.

Bruder GE, Quitkin FM, Stewart JW, Martin C, Voglmaier MM, Harrison WM (1989). Cerebral laterality and depression: differences in perceptual asymmetry among diagnostic subtypes. J Abnorm Psychol 98: 177-186.

Bruder GE, Stewart JW, McGrath PJ, Ma GJ, Wexler BE, Quitkin FM (2002). Atypical depression: enhanced right hemispheric dominance for perceiving emotional chimeric faces. J Abnorm Psychol 111: 446-454.

Derogatis LR (1977). SCL-90: Administration, Scoring and Procedures Manual-I for the $R$ (revised) Version and Other Instruments of the Psychopathology Rating Scales Series. Johns Hopkins University School of Medicine: Chicago.

Emslie GJ, Heiligenstein JH, Wagner KD, Hoog SL, Ernest DE, Brown E et al (2002). Fluoxetine for acute treatment of depression in children and adolescents: a placebo-controlled 
randomized clinical trial. J Am Acad Child Adolesc Psychiatry 41: $1205-1215$

Emslie GJ, Rush AJ, Weinberg WA, Kowatch RA, Hughes CW, Carmody $\mathrm{T}$ et al (1997). A double-blind, randomized, placebocontrolled trial of fluoxetine in children and adolescents with depression. Arch Gen Psychiatry 54: 1031-1037.

Fotiou F, Fountoulakis KN, Iacovides A, Kaprinis G (2003). Pattern-reversed visual evoked potentials in subtypes of major depression. Psychiatry Res 118: 259-271.

Fountoulakis KN, Iacovides A, Gerasimou G, Fotiou F, Ioannidou C, Bascialla F et al (2004). The relationship of regional cerebral blood flow with subtypes of major depression. Prog Neuropsychopharmacol Biol Psychiatry 28: 537-546.

Geller B, Reising D, Leonard HL, Riddle MA, Walsh BT (1999). Critical review of tricyclic antidepressant use in children and adolescents. J Am Acad Child Adolesc Psychiatry 38: 513-516.

Geracioti Jr TD, Loosen PT, Orth DN (1997). Low cerebrospinal fluid corticotropin-releasing hormone concentrations in eucortisolemic depression. Biol Psychiatry 42: 165-174.

Hazell P, O'Connell D, Heathcote D, Henry D (2002). Tricyclic drugs for depression in children and adolescents. Cochrane Database Syst Rev 1: Art. no.: CD002317.

Heller W (1993). Gender differences in depression: perspectives from neuropsychology. J Affect Disord 29: 129-143.

Joyce PR, Mulder RT, Luty SE, Sullivan PF, McKenzie JM, Abbott $\mathrm{RM}$ et al (2002). Patterns and predictors of remission, response and recovery in major depression treated with fluoxetine or nortriptyline. Aust N Z J Psychiatry 36: 384-391.

Keller MB, Ryan ND, Strober M, Klein RG, Kutcher SP, Birmaher B et al (2001). Efficacy of paroxetine in the treatment of adolescent major depression: a randomized controlled trial. J Am Acad Child Adolesc Psychiatry 40: 762-772.

Kendell RE (1989). Clinical validity. Psychol Med 19: 45-55.

Kendler KS, Eaves LJ, Walters EE, Neale MC, Heath AC, Kessler RC (1996). The identification and validation of distinct depressive syndromes in a population-based sample of female twins. Arch Gen Psychiatry 53: 391-399.

Klein DF (1974). Endogenomorphic depression: a conceptual and terminological revision. Arch Gen Psychiatry 31: 447-454.

Klein DF (1989). The pharmacological validation of psychiatric diagnosis. In: Robins L, Barrett J (eds). Validity of Psychiatric Diagnosis. Raven: New York. pp 203-216.

Klein RG, Mannuzza S, Koplewicz HS, Tancer NK, Shah M, Liang V et al (1998). Adolescent depression: controlled desipramine treatment and atypical features. Depress Anxiety 7: $15-31$.

Korn A, Da Prada M, Raffesberg W, Allen S, Gasic S (1987). Tyramine pressor effect in man: studies with moclobemide, a novel, reversible monoamine oxidase inhibitor. J Neural Transm 26(Suppl): 57-71.

Lam RW, Stewart JN (1996). The validity of atypical depression in DSM-IV. Compr Psychiatry 37: 375-383.

Liebowitz MR, Quitkin FM, Stewart JW, McGrath PJ, Harrison WM, Markowitz JS et al (1988). Antidepressant specificity in atypical depression. Arch Gen Psychiatry 45: 1290137.

Mandoki MW, Tapia MR, Tapia MA, Sumner GS, Parker JL (1997). Venlafaxine in the treatment of children and adolescents with major depression. Psychopharmacol Bull 33: 149-154.

Matza LS, Revicki DA, Davidson JR, Stewart JW (2003). Depression with atypical features in the National Comorbidity Survey: classification, description, and consequences. Arch Gen Psychiatry 60: 817-826.

McGinn LK, Asnis GM, Rubinson E (1996). Biological and clinical validation of atypical depression. Psychiatry Res 60: 191-198.
McGrath PJ, Stewart JW, Janal MN, Petkova E, Quitkin FM, Klein DF (2000). A placebo-controlled study of fluoxetine versus imipramine in the acute treatment of atypical depression. Am J Psychiatry 157: 344-350.

Nierenberg AA, Pava JA, Clancy K, Rosenbaum FJ, Fava M (1996). Are neurovegetative symptoms stable in relapsing or recurrent atypical depressive episodes? Biol Psychiatry 40: 691-696.

Parker G, Roy K, Mitchell P, Wilhelm K, Malhi G, Hadzi-Pavlovic D (2002). Atypical depression: a reappraisal. Am J Psychiatry 159: $1470-1479$.

Perugi G, Akiskal HS, Lattanzi L, Cecconi D, Mastrocinque C, Patronelli A et al (1998). The high prevalence of 'soft' bipolar (II) features in atypical depression. Compr Psychiatry 39: 63-71.

Posternak MA, Zimmerman M (2002). Partial validation of the atypical features subtype of major depressive disorder. Arch Gen Psychiatry 59: 70-76.

Quitkin FM, McGrath PJ, Stewart JW, Harrison W, Tricamo E, Wager SG et al (1990). Atypical depression, panic attacks, and response to imipramine and phenelzine: a replication. Arch Gen Psychiatry 47: 935-941.

Quitkin FM, Stewart JW, McGrath PJ, Liebowitz MR, Harrison WM, Tricamo E et al (1988). Phenelzine versus imipramine in the treatment of probable atypical depression: defining syndrome boundaries of selective MAOI responders. Am J Psychiatry 145: 306-311.

Rabkin JG, Stewart JW, Quitkin FM, McGrath PJ, Harrison WM, Klein DF (1996). Should atypical depression be included in DSM-IV? In: Widiger TA, Frances AJ, Pincus HA, Ross R, First MB, Davis WW (eds). DSM IV Sourcebook. American Psychiatric Association: Washington, DC. Vol. 2, pp 239-260.

Robins E, Guze SB (1970). Establishment of diagnostic validity in psychiatric illness: its application to schizophrenia. Am J Psychiatry 126: 983-987.

Sargant W (1960). Some newer drugs in the treatment of depression and their relationship to other somatic treatments. Psychosomatics 1: 14-17.

Spitzer RL, Endicott J, Robins E (1978). Research diagnostic criteria: rationale and reliability. Arch Gen Psychiatry 35: 773-782.

Stewart JW, Garfinkel R, Nunes EV, Donovan S, Klein DF (1998). Atypical features and treatment response in the National Institute of Mental Health Treatment of Depression Collaborative Research Program. J Clin Psychopharmacology 18: 429-434.

Stewart JW, McGrath PJ, Quitkin FM (2002). Do age of onset and course of illness predict different treatment outcome among DSM IV depressive disorders with atypical features? Neuropsychopharmacology 26: 237-245.

Stewart JW, McGrath PJ, Rabkin JG, Quitkin FM (1993). Atypical depression. A valid clinical entity? Psychiatr Clin North Am 16: 479-495.

Wagner KD, Jonas J, Findling RL, Ventura D, Saikali K (2006). A double-blind, randomized, placebo-controlled trial of escitalopram in the treatment of pediatric depression. J Am Acad Child Adolesc Psychiatry 45: 280-288.

Whittington CJ, Kendall T, Fonagy P, Cottrell D, Cotgrove A, Boddington E (2004). Selective serotonin reuptake inhibitors in childhood depression: systematic review of published versus unpublished data. Lancet 363: 1341-1345.

Wong ML, Kling MA, Munson PJ, Listwak S, Licinio J, Prolo P et al (2000). Pronounced and sustained central hypernoradrenergic function in major depression with melancholic features: relation to hypercortisolism and corticotropin-releasing hormone. Proc Natl Acad Sci USA 97: 325-330.

See related article by Thase on page 2633 . 